\title{
Dança Também é Bom Para Vender: Usos de representações de dança no programa "o boticário na dança"
}

\author{
Rafael Guarato \\ Universidade Federal de Goiás - UFG, Goiânia, Brasil \\ E-mail: rafaelguarato@ufg.br \\ Irislene Silva de Oliveira \\ Universidade Federal de Goiás - UFG, Goiânia, Brasil \\ E-mail: irislenesilva@hormail.com
}

\section{Resumo}

O presente trabalho investiga como a dança foi veiculada no programa "O Boticário na Dança", partindo da análise do vídeo publicitário "O Boticário na Dança - Beleza em movimento", com intuito de compreender por quais meios a dança consegue valoração e sentido a ponto de fomentar consumo. Nesse sentido, propomos que a dança possui uma economia própria capaz de mobilizar sentidos para mercados. Para tanto, o texto estabelece diálogos centrais com debates acerca dos conceitos de indústria cultural, representação e mercadoria pela perspectiva da antropologia contemporânea e da história cultural.

\section{Palavras-chave}

Dança. Representação. Mercadoria.
Abstract

The present text investigates how the dance was carried out in the program "O Boticário na Dança", starting from the analysis of the advertising video "O Boticário na Dança - Beleza em movimento", in order to understand how dance can appreciate and feel how it can promote consumption. In this sense, dance has an economy and mobilizes meanings for a market. For this, the text establishes central dialogues with debates about the concepts of cultural industry, representation and commodity from the perspective of contemporary anthropology and cultural history.

Keywords

Dance. Representation. Commodity. 
O estudo acerca das interlocuções e interações entre dança e mercado tem recentemente recebido a atenção de estudiosos do campo dos estudos em dança ao redor do mundo. Exemplo desse movimento foi a publicação do $35^{\circ}$ volume da Dance Research, The Journal of the Society for Dance Research, o periódico acadêmico europeu mais prestigiado da área, que em 2017 publicou um dossiê temático sobre Dance Economies. Contudo, apesar de ter despertado esse interesse, o desenvolvimento de vinculações epistemológicas e de entendimentos acerca do assunto ainda resguarda um caminho consideravelmente longo de pesquisas que deverão surgir, tendo em vista a imensidão e a diversidade dos serviços e produtos ofertados pelos profissionais da área da dança e a complexidades de suas relações com a sociedade.

Nos entremeios entre economia da dança e mercados de dança, entendemos ser salutar situar o leitor sobre o como compreendemos a dança e sua definição de mercadoria. Para isso, é elucidativo o trato que o antropólogo Igor Kopytoff (1986) nos oferece sobre o que é uma mercadoria, definindo-a como algo que tem um determinado valor de uso e que em determinadas circunstâncias pode ser trocada, geralmente, por algo mensurado como de idêntico valor. Por esse viés, não existe algo, coisa ou serviço que é ou não mercadoria a priori, mas interações culturais que conseguem agregar a coisas, serviços e obras, o valor de troca necessário para que assuma a condição de mercadoria.

Sobre esse prisma epistemológico a dança pode ser mercadoria, deslocando a atenção do maniqueísmo enganador da relação entre arte e mercado para adentrar aos entendimentos de como a dança consegue trocar seus serviços e produtos, compreendendo quais os sentidos e dinâmicas culturais específicas alicerçam estas trocas
(Guarato, 2018). Neste estudo em particular, nosso foco se encontra em entender como a empresa de cosméticos 0 Boticário ${ }^{1}$ conseguiu fazer da dança uma moeda de troca para fornecer sentido e agregar valor simbólico/monetário à sua marca. Ou seja, como não é dança em si o objeto de comércio da empresa, nossa atenção se concentra em entender como a dança foi recrutada para auxiliar no processo de fornecer sentidos e valores aos produtos por ela comercializados?

Tal agenciamento da dança foi realizada por meio do programa "O Boticário na Dança", que teve início no ano de 2013 contando com três eixos norteadores: o festival "O Boticário na Dança"2, o patrocínio de projetos voltados para a dança ${ }^{3}$ e a criação do canal de dança ${ }^{4}$.

1 Fundada por Miguel Krigsner no ano de 1977, no Estado do Paraná, a empresa "O boticário" começou primeiramente como uma farmácia de manipulação, atualmente a "O Boticário" está entre as maiores redes de franquia do mundo no segmento de drogaria e perfumaria, e faz parte do "Grupo Boticário" juntamente com outras três empresas: "Eudora", "Quem disse Berenice?" e "The Beaty Box" que atuam no mesmo segmento.

2 O Festival O Boticário na Dança foi realizado entre os anos de 2013 à 2015 e se propôs a tentar contemplar o vasto panorama da dança, viabilizou a vinda de companhias renomadas do cenário internacional para apresentações, em alguns casos inéditas no Brasil, e apresentações de algumas companhias nacionais de reconhecimento legitimado no campo. Por meio de artistas de marca do mundo da dança, ao convidar grupos que se encontram no mainstream do campo, o Programa agrega valor a marca que passa a ser vinculada como a promotora de eventos na arte, especificamente da dança, à modelo do ocorrido nas décadas de 1980 e 1990 com o Carlton Dance Festival. Centrado nas regiões Sul e Sudeste do país, o Festival contratou artistas como: Mimulus (BH), Quasar (GO), Grupo de Rua do Coreografo Bruno Beltrão (RJ), Hofesh Schechter Company (Inglaterra), Peeping Tom (Bélgica), Maribor Ballet (Eslovênia), Shen Wei Dance Arts (Estados Unidos), Israel Galván (Espanha) e Akram Khan (Bangladesh), a companhia Culberg Ballet (Suécia), o Michael Clark Company (Inglaterra), Batsheva Ensemble (Israel), o grupo TAO Dance Theater (China), dentre outros.

3 Os eventos e projetos apoiados pelo programa fazem uso do mecanismo de renúncia fiscal através da Lei $n^{\circ} 8.313$, conhecida como Lei Rouanet, em que instituiu o Programa Nacional de Apoio a Cultura (Pronac), implementado por meio do três mecanismos de financiamento: Fundo Nacional da Cultura (FNC), Fundos de Investimento Cultural e Artístico (Ficart) e o Incentivo a projetos culturais. Entre 2013 e 2016 o Programa foi direcionado especificamente à dança. Já o edital do ano de 2017 deixou de ser voltado apenas para a área da dança passando a contemplar todas as demais manifestações artísticas.

4 Disponível em: < diversao.terra.com.br/arte-e-cultura/dança > 
Para não extrapolar os limites textuais deste artigo, optamos por demonstrar como a dança foi usada pelo programa "O Boticário na Dança" através do vídeo publicitário "O Boticário na Dança - Beleza em movimento" 5 , produzido em 2015 pela Dueto Produções ${ }^{6} \mathrm{e}$ disponibilizado no canal da empresa "O Boticário", na plataforma do Youtube no dia 27 de maio de 2015 e cujo conteúdo foi e ainda é veiculado antes das mostras, espetáculos e demais ações fomentadas pelo programa.

Nos atendo preliminarmente aos aspectos de conteúdo do vídeo, são apresentados nos sessenta e um segundos de sua duração, dançarinos que apresentam movimentações corporais vinculadas a estéticas de danças específicas, como o Balé Clássico, o Jazz, o Breaking, o Freestyle, o Vogue e a Dança de Salão, que em si são linguagens que possuem estéticas diferentes, mas que estão representadas no vídeo de forma indiscriminada. São veiculados doze dançarinos ao todo, sendo sete mulheres, cinco homens e dois deles negros. As alternâncias entre takes de câmera no vídeo são rápidas, os dançarinos são apresentados sequencialmente, fazendo movimentos ágeis e virtuosos. Existe um recurso de edição no vídeo que sequencializa e fornece uma coerência nas sequências das imagens, que consiste na alternância entre dançarinos com ênfase em movimentações que se conectam similaridade de execução dos movimentos (abertura, giros, perna estendidas; braço em uma posição específica) dando ao vídeo uma ideia de continuidade em que as estéticas de dança presentes se comuniquem e se complementem. A sequência de movimentação contínua

\footnotetext{
5 Disponível em: < https://www.youtube.com/watch?v=NDXNmUJvDnE >. Acesso em 06/05/2019.

6 O Dueto Produções tem por característica realizar eventos e atividades que associam cultura e entretenimento com marcas, estando na produção de eventos nacionais como: Free Jazz Festival, Carlton Dance Festival, Carlton Arts, Tim Festival, BMW Jazz Festival, Festival O Boticário na Dança e Preciosidades Vivara.
}

de cada dançarino mostrado no vídeo varia entre meio a quatro segundos, tendo trinta e nove trocas de sequencias de imagens/ movimentos de um dançarino para o outro.

Todos os dançarinos(as) presentes no vídeo apresentam características que os aproximam: um corpo magro, torneado, longilíneo, flexível, ágil, disposto, jovem e pulsante, passando a sensação de alegria, energia e esbanjo de saúde - o que é perceptível nas movimentações que realizam e que está carregada de virtuosismo e domínio de técnicas de dança. As mulheres se utilizam de movimentos que reverberam nos cabelos, trabalhando a ideia de charme e replicando a concepção hegemônica de feminilidade em suas movimentações. A postura corporal, sempre reta e alongada dá embasamento para o corpo viril, forte, pronto.
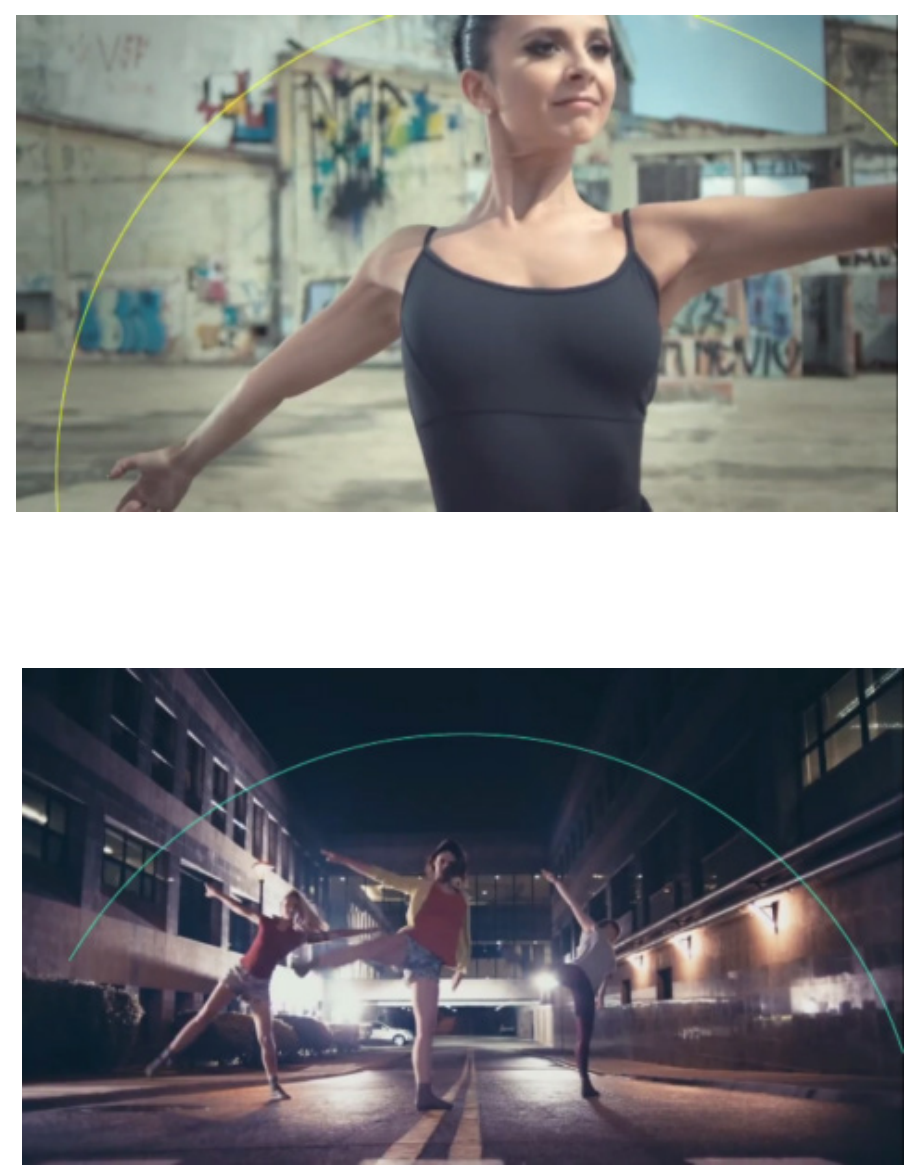

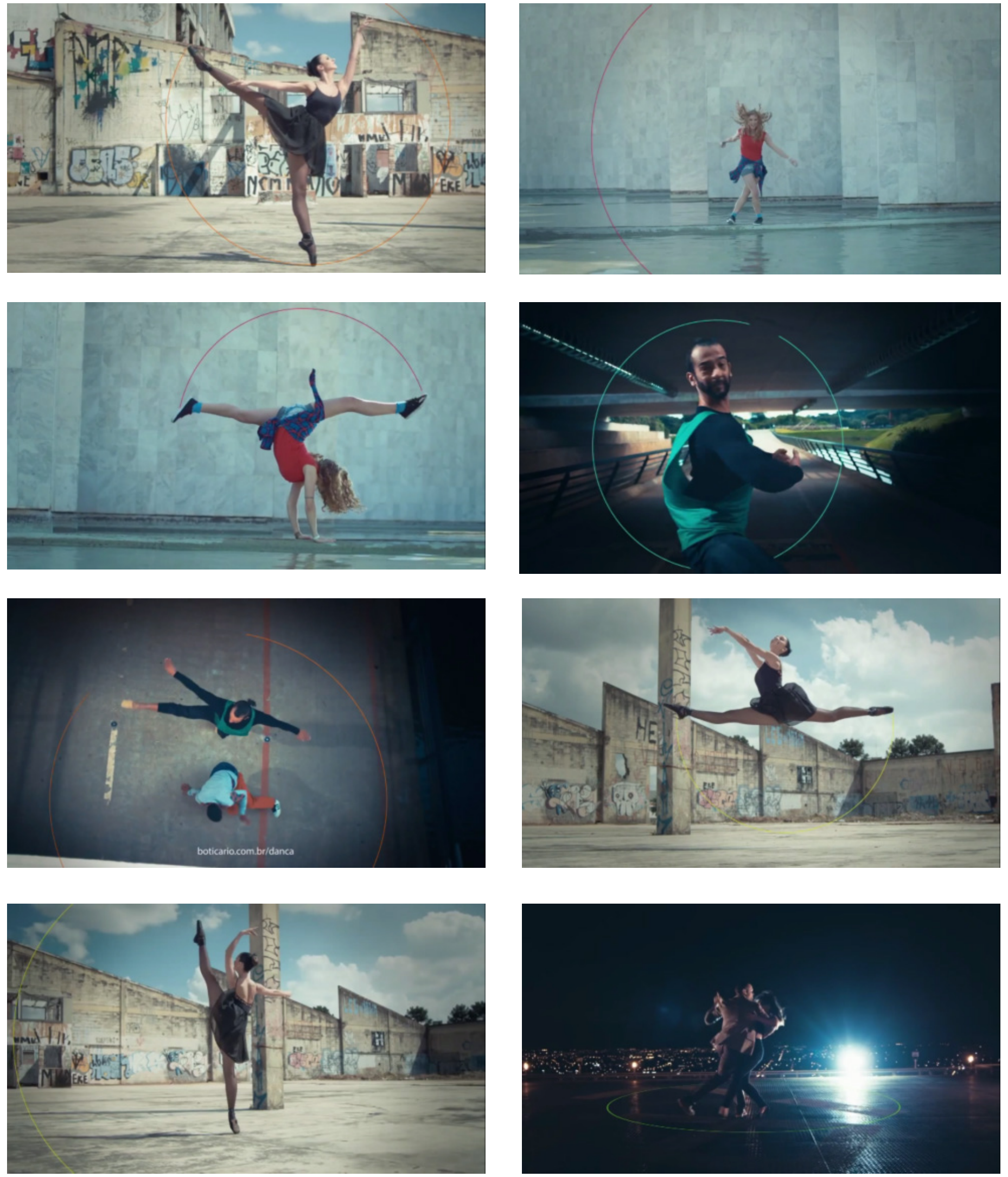


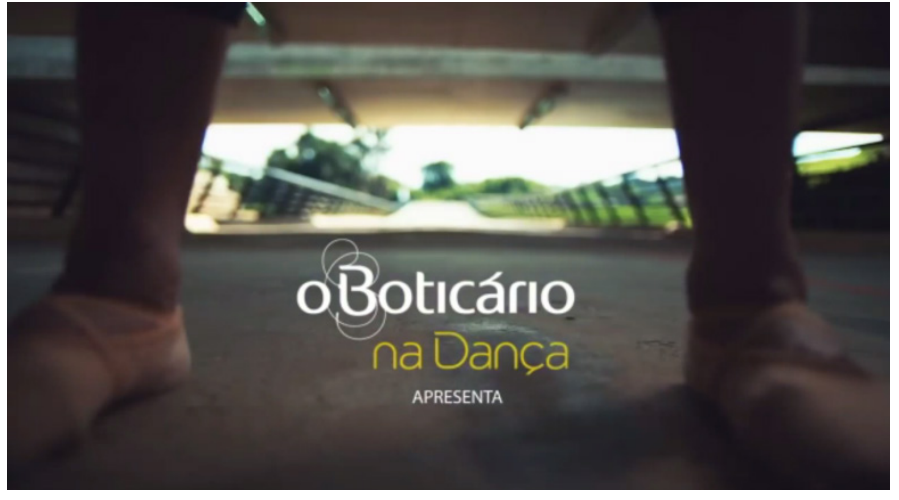

Acervo Pessoal: Imagens capturadas do vídeo O Boticário na dança - Beleza em movimento

Outra presença importante no vídeo que facilmente nos revela o vínculo conceitual com o paradigma renascentista/cartesiana de corpo mecanizado, são as linhas geometrais que desenham o percurso feito pelo movimento dos bailarinos, destacando a capacidade técnica destes em fazer movimentos virtuosos, negligenciando outros entendimentos sobre corpo e dança arrolados nos debates no campo desde o século XIX. Tal inserção no vídeo faz referencia ao logotipo do programa o "Boticário na Dança" que conta com linhas em formato arredondado, círculo e semicírculo, que saem da letra "B" de "Boticário" fazendo uma comparação direta entre a marca e o conceito de beleza pretendido a partir dos movimentos realizados no vídeo. São onze movimentos que aparecem destacados por essa linha, sendo sete deles provenientes de movimentos do balé em sua formatação clássica, oito desses dez movimentos são feitos com pernas que são estendidas e direcionadas para o alto.

A nível descritivo, são essas as informações que a propaganda nos fornece em termos de dança, mas, como isso pode ser considerado belo ou funcione como acionador de um entendimento de beleza? E mais evasivo de mensurar, como esse emaranhado de movimentos assumem o aspecto de mercadoria? Nossa hipótese é que sozinha, a dança não consegue garantir esses significados de beleza e de mercadoria a seu fazer, necessitando de uma complexa rede de convenções sociais para que a operação com características de mercado sejam funcionais.

Vendendo sentidos de dança através de meios massivos e da indústria da cultura

No vídeo descrito o que se vende não é a dança em si, mas os sentidos que ela agrega a seu fazer. É com esse diagnóstico que prosseguimos para acrescentar que é necessário compreendermos quais os sentidos envolvidos que são eficazes o suficiente para tratar a dança como meio de veicular um entendimento de "beleza em movimento"? Para entendermos essas questões temos de minuciar o agenciamento de três fatores associados que foram necessários para o funcionamento da propaganda aqui analisada: a) escolha de uma representação do que é dança já disponível no imaginário social; b) arregimentar padrões estéticos e modos de exibição dos corpos segundo uma representação contemporânea do que é beleza; c) recorrência aos meios massivos de comunicação como lócus privilegiado para mediar as representações de dança e beleza eleitas.

Tendo em vista que a dança se fez como arte, tradicionalmente, através de um instrumento peculiar, o corpo humano em movimento, sua exibição e apreciação também estiveram alicerçadas de forma exclusiva durante muito tempo pelo recurso fisiológico do olhar, sendo apreciada através do fenômeno da visualidade. Tendo essa forma de existir e se apresentar, corpo e imagem foram coisas inseparáveis para existência da dança na condição de arte no ocidente, ou, em outras palavras, a dança se organizou e se publicou ao longo dos anos através de representações de corpos em movimento. 
Dada esta condição de percepção visual como mediadora da relação entre aquele que faz e aquele que aprecia, o conceito de representação é central no processo de compreensão de intenções e transmissões de sentidos envolvendo a dança que é veiculada pela propaganda da $\mathrm{O}$ Boticário. $\mathrm{O}$ anúncio audiovisual se faz por meio de imagens que funcionam através de representações, essas imagens assumem a condição de representação por não serem a realidade em si mesma e sim uma (re)apresentação dessa realidade através de recursos tecnológicos.

Tal representação é aqui entendida como fenômeno de substituição, isto é, quando uma coisa, o representante, substitui outra, o representado, sendo que essa relação em que uma coisa está pela outra, é construída pelos diferentes grupos que compõem a sociedade. O historiador Roger Chartier (1991, p. 184) descreve a relação de representação como uma "imagem presente e um objeto ausente, uma valendo pelo outro porque lhe é homóloga". Esse entendimento de Chartier nos permite adentrar a uma das dinâmicas da representação, que é seu potencial de substituir ou de produzir situações, pessoas, intenções, emoções. Portanto, o que temos nos vídeos de propaganda não é a dança sendo dançada, mas uma dança que já foi dançada um dia por alguém e que nos é (re)apresentada por um aparato técnico de reprodução, que permite sua replicação em lugares e situações onde o "original" não se faz presente. Grosso modo, a representação em formato de vídeo possui um alcance de publico imensuravelmente maior que a presença física do dançarino pelo seu potencial de (re)apresentar.

Mas há uma outra dinâmica na operação de representação que nos é importante aqui. O historiador da arte Ernest Hans Gombrich nos esclarece que apesar da ideia de representação está ligada a qualidade de substituir algo, essa substituição não se pauta tanto pela semelhança com aquilo a que se substitui, mas sim pela função similar entre eles, ou seja, a função e não a forma é o fator comum entre aquilo que é representado e a própria representação.

O gato corre atrás da bola como se fosse um rato. $O$ bebê suga o polegar como se fosse um peito. Em certo sentido, a bola 'representa' um rato para o gato; e o polegar, um peito para o bebê. Mas, também aqui, a 'representação' não depende de semelhanças formais, a não ser as exigências mínimas da função. (Gombrich, 1999, p. 4)

Sabemos que a analogia pode parecer esdrúxula, mas a intenção é notarmos que o objeto ou assunto representado, por ser algo socialmente construído, pode ter significados diferentes para grupos distintos; porém, quando esses grupos a compreendem de uma mesma forma é um indicativo de que essas pessoas partilham entendimentos similares sobre aquilo a que se refere a representação, tornando possível a atribuição de uma mesma interpretação para uma determinada representação. Se a mesma forma pode representar coisas diferentes para determinadas sociedades, será a assimilação de seu significado que irá depender das convenções sociais a que esteja inserida e das funções a que se atribuem a ela. As imagens de dança contidas no vídeo publicitário passam a ser compreendidas como uma indicação de algo, e a competência dos profissionais que trabaIharam para produzir aquelas imagens está ligada diretamente a capacidade, mesmo que mínima, do leitor em interpretar e atribuir significados a aquilo que lhe é apresentado.

Pensada por esse paradigma, a imagem do corpo em movimento como dança é uma forma de representação que a própria área da dança entendida como arte comungou e disseminou até as primeiras décadas do sé- 
culo XX. No entanto, as danças, movimentos e sentidos contidos no vídeo que buscam auxiliar na construção da "beleza em movimento" não guardam nenhuma relação com as preocupações da dança como linguagem artística na contemporaneidade. Ora, se não foi no diálogo com a dança entendida como arte na contemporaneidade, quais são os pressupostos que suportam os sentidos promovidos pela propaganda e seus usos da dança?

A estrutura que fornece sentidos à propaganda, que permitiu selecionar pessoas, lugares, situações, estéticas e movimentos foram orientados por representações de dança e beleza encontrados nos meios massivos de comunicação. A presença da dança em diferentes suportes midiáticos tornou-se um evento corriqueiro na atualidade. Comumente assistimos dança na abertura de programas televisivos em rede aberta, programas e quadros competitivos dedicados especificamente à dança e propagandas com dançarinos(as) de diferentes estéticas sendo propagados pelos meios de comunicação de alcance massivo.

Dentre os programas e quadros televisivos que passaram a veicular a dança na atualidade da televisão brasileira aberta, destacamos o so you think you can dan$\mathrm{ce}^{7}$, a "a dança dos famosos", o dancing Brasil e o "se ela dança eu danço"10, que trazem uma dança espetacularizada e produzida para seduzir o olhar do espectador

\footnotetext{
7 Programa de competição de dança de origem estadunidense, que vai ao ar nos Estados Unidos Desde o ano de 2005 e com versões em vários países dos continentes americanos e europeu.

8 Quadro de apelo popular do Programa Domingão do Faustão, apresentado por Fausto Silva, que vai ao ar aos domingos pela Rede Globo de Televisão desde o ano de 2005 e se organiza em apresentações de diferentes estéticas de dança através de duplas formadas por um homem e uma mulher.

9 Programa apresentado pela Xuxa Meneghel na Tv Record e que vai ao ar nas segundas à noite, tendo estreado no início de 2017. 10 Programa apresentado por Lígia Mendes e Beto Marden, tendo como jurados Lola Melnick, João Wlamir e Jarbas Mello, que foi ao ar pelo SBT tendo sido estreado no início de 2011 contando com apenas duas temporadas.
}

por meio de uma ideia de beleza específica, sempre atrelada ao virtuosismo corporal de aspecto técnico. Há portanto nos últimos 15 anos da televisão brasileira, uma constante apresentação de corpos dançando uma diversidade de estéticas e que esboçam similitudes que as tornam próximas e passíveis de ocupar um contrato numa economia da dança relacionada aos meios massivos.

As características que compõem esses corpos dançantes nos meios massivos ainda não desfrutam de conceitualização que satisfaça à complexidade e diversidade de danças. A pesquisadora de dança estadunidense Susan Foster (2018) por exemplo, tem realizado um recente empenho em tentar conceituar corpos que na cena contemporânea tem conseguido ser contratado. Nesse esforço a autora procedeu por eliminação de características e propôs três grandes modelos de corpo que encontra espaço no mercado global de companhias de dança, sendo: a) o "corpo balético" que é dotado de técnica do balé mas não necessariamente aplicado estritamente a estética cênica do balé; o "corpo industrial" como aquele presente nos meios midiáticos e propagador de uma vitalidade ilusória e disposição inigualável; e o "corpo despojado" que se apresenta preocupado com questões cinesiológicas e aproveitamento das singularidades presentes em cada corpo.

Não nos cabe neste texto atermo-nos aos meandros desses conceitos, mas vale ressaltar que ao estabelecer essa tríade, Foster simplifica elementos que interagem entre as categorias e que são importantes para uma análise criteriosa dos processos de valoração mercadológica da dança. Como nos demonstra a propaganda que busca "a beleza em movimento", tanto o corpo balético quanto o corpo industrial podem servir ao mesmo propósito e conferir os mesmos sentidos à uma ideia de dança 
que seja capaz de vender o belo ou o desejo por alcançar esse belo. No modo como as imagens de dança se sucedem no vídeo comercial da O Boticário, o corpo balético também é convocado a servir às dinâmicas e convenções simbólicas que Foster atribuiu exclusivamente ao corpo industrial.

Todas as danças presentes no vídeo possuem em comum o perfil jovial, incansável, versátil e virtuoso, ágil, dotado de uma prontificação para ação, alegre e que sugere otimismo e positividade no ato de dançar. $\mathrm{E}$ esse agrupamento de estéticas diferentes com a habilidade de sugerir o mesmo sentido não é um mérito exclusivo, apesar de muito poderoso, dos meios massivos ou da indústria da cultura, pois a produção da propaganda foi uma escolha dos dirigentes e setor de marketing da O Boticário, contando com as astúcias destes em fabricar e agrupar sentidos à dança (ou de retirar seus sentidos para inserirem outros). A questão é não perdermos de vista que "os significados lidos de formas idênticas por pessoas diferentes nos dizem mais sobre os leitores do que sobre as formas." (Gombrich, 1999, p.8) O vídeo do programa "O Boticário na dança", fez uso de sentidos disseminados sobre dança que se encontravam disponíveis no meio social entre grupos diversos, de culturas distintas, com ou sem conhecimento ou mesmo vivência prévia com a dança, articulando uma forma para que entrassem em contato com a mesma, levando até eles direcionamentos para uma leitura específica do que é dança, mas cujos conteúdos já dispunham de exemplares prévios disponíveis no meio cultural dos residentes no Brasil através da telona.

Outra habilidade de aglutinação de sentidos à dança presente no vídeo publicitário necessários para se sugerir a "beleza em movimento", provém do uso de um conceito contemporâneo midiático e hegemônico (Williams, 1969) de beleza que vem edifi- cando um processo narcisista do chamado "culto ao corpo". O culto do corpo como algo vinculado à ideia de belo e saudável - os dois sempre juntos - que em séculos passados seria mal visto e até condenado, passou a partir dos séculos $X X$ e $X X I$, a se tornar não apenas aceitável, mas algo quase necessário para a realização pessoal do individuo. Conforme descreve a historiadora Denise B. Sant'anna (2004), anteriormente ao século $X X$ a beleza era um atributo de poucos e era percebida como um dom divino. O cuidado com corpo não era difundido, pois, como pregava a moral cristã, ele representava o cárcere da alma e tratado como foco dos pecados humanos e não deveria portanto, ser tão valorizado. A beleza era natural e aquela que não a tinha era tratada como vítima de uma fatalidade.

Com o advento tecnológico/científico durante o século $\mathrm{XX}$ e as revoluções das minorias, a beleza migrou de algo inato para algo que se conquista. Aquela ou aquele desprovido(a) de beleza e com ela um imaginário de saúde, passou a ser tido socialmente como descuidado consigo mesmo, tendo em vista os recursos de cirurgias, cosméticos e indústria têxtil disponíveis. Mas para ser belo segundo as normativas que estão sendo edificadas na contemporaneidade, é preciso ter acesso aos meios de consumo de cosméticos ou poder aquisitivo para intervenções plásticas e é aqui que nos interessa esse assunto. O belo contemporâneo no Brasil é eurocentrado e que supõe aceitar minorias, com isso ele se configura como predominantemente branco, com aspecto magro e tonificado, se apresenta de modo simétrico, organizado e sempre limpo e alegre. Encontrado apoio na mídia e nos novos padrões de consumo modernos, o corpo começou a tomar lugar nas propagandas que incluíram entre as práticas corporais promovedoras de bem-estar, saúde e beleza, a dança des- 
de as últimas décadas do século passado. ${ }^{11}$

Lidando com essas características da representação de beleza e saúde, a propaganda utiliza de imagens que funcionam como substitutos de algo não pela sua forma, mas pela função que cumpre os corpos em movimento e suas características. Tendo em vista que estando "mais sedutores que no passado, os anúncios insinuam, sugerem e prometem felicidade" (Sant'anna, 2005, p.176), o objetivo principal do vídeo analisado consiste em influenciar as atitudes e escolhas dos consumidores. A propaganda trabalha com os desejos, fantasias e sonhos do individuo, optando por uma comunicação que encante e seduza ao invés de trabaIhar apenas com elementos pertencentes ao real material e suas contradições, o que obviamente limitaria sua eficácia. Mas, ao mesmo tempo, não abandona por completo esse real, sendo ele o suporte que permite tornar crível seu conteúdo. É com essa dinâmica que o slogan do vídeo publicitário "beleza em movimento" faz uso de algumas representações de corpos com a finalidade de dar publicidade ao programa "O Boticário na dança", relacionando o conceito de beleza, que é corporificado na propaganda através da dança, à empresa "O Boticário".

\section{Da "beleza em movimento", o que sobra de (para a) dança?}

A arte no ocidente de diferentes maneiras, se municiou da representação como mecanismo para comunicar os temas e assuntos que lhes eram importantes em determinada época e lugares específicos. O corpo e a dança se tornam, comumente, representantes de temas diversos, adquirindo um significa-

\footnotetext{
11 A exemplo disso é ilustrativo as publicações da Revista Dançar, periódico mensal que circulou por uma década entre os anos de 1982 e 1992, onde se pode notar pelo conteúdo das materias e inclusive pela presença nas modelos de capa, a existência da vinculação entre dança, beleza e saúde.
}

do específico quando ligada aos interesses daqueles que a praticam ou propagam. Ao ser escolhida para integrar o programa "O Boticário na Dança", caberia à dança a função de representar, tal como diz o slogan, "a beleza em movimento", vinculando o conceito de dança a um corpo bem preparado/tonificado, técnico, viril, forte e belo, características que também passam a representar, mesmo que indiretamente, a marca "O Boticário" e os produtos de cosméticos por ela comercializados. Nessa condição, a dança mobiliza uma economia de sentidos capaz de ancorar um outro mercado, que não é o de dança.

$O$ que atribui sentido e também valoração aos corpos dançantes no vídeo publicitário, é a função que ela cumpre ao representar e não necessariamente o que os e as dançarinos(as) representam ou pensavam ou pretendiam representar. Mesmo contando com corpos dançantes, com características físicas particulares, fazendo menção a estilos de dança distintos e veiculando lugares diferentes, o conjunto das imagens, movimentos, corpos, lugares e edição possuem uma única função orientadora, a de traduzir e corporificar o que o programa entende como "Beleza em movimento", ligando-a a marca O Boticário.

Por essa configuração, as danças, os corpos, os lugares e as estéticas apresentadas não nos contam sobre as próprias danças em si. As danças que aparecem no vídeo estão vazias de sentido em si mesmas, as movimentações dos corpos e da câmera se contentam em apresentar um corpo técnico e bem preparado/tonificado, com alegria e energia pulsante proveniente do jazz e danças urbanas, mostrando que o único sentido que se pode atribuir a essas movimentações no vídeo é a de conterem ou edificarem uma ideia de "Beleza em movimento".

No entanto, as danças, movimentos e os modos como estão presentes e utilizados no vídeo publicitário não encontram respal- 
do nas discussões e debates que fazem da dança uma linguagem artística, pelo menos da segunda metade da década de 1950 até nossos dias (Bannes, 1999; Lepecki, 2006). As guinadas conceituais e estéticas ocorridas ao longo do século XX se encarregaram de relegar à dança o papel representacional no modelo mimético, assim como a ideia de que a arte trata (de modo kantiano e não cosmético) daquilo que é "belo", se esvaiu com a modernidade estética em todas as artes já nos idos do novecentos fin-de-siècle. Portanto, as dinâmicas, procedimentos, conceitos e preocupações que regem o fazer da dança na condição de arte estão alijados desse processo. A questão é que essa distinção não é apresentada ao espectador no momento em que o vídeo é exibido.

Para um olhar mais próximo das dificuldades e problemas enfrentados nos processos de valoração monetária da dança na sociedade, o modo de recrutar a dança praticado pela "O Boticário" - apesar de dar visibilidade à linguagem Dança e contribuir para uma economia da dança pautada num imaginário moderno e hegemônico sobre o que socialmente é entendido como dança -; replica e aumenta a ignorância acerca das preocupações daqueles que entendem e se dedicam a compreender, pensar, produzir e circular dança com as preocupações do campo artístico. E com isso, afunilando cada vez mais o fosso que separa o espectador comum do modo de produção artístico sempre em vias de especialização.

\section{Referências}

BANNES, Sally. Greenwich Village 1963: avant-garde. Performance e o corpo efervescente. Rio de Janeiro: Rocco, 1999.

CHARTIER, Roger. O mundo como representação. Estudos avançados, São Paulo, 11, 5, pp. 173/191, 1991.
FOSTER, Susan. Dança e o cenário global. In: HERCOLES, Rosa; TEIXEIRA, Ana; SANTOS, Eleonora (orgs.). ANDA: 10 anos de pesquisas em dança. Salvador: ANDA, 2018. p. 119-136.

GOMBRICH, Ernest Hans. Meditações sobre um cavalinho de pau e outros ensaios sobre a teoria da arte. São Paulo: Editora da Universidade de São Paulo, 1999.

GUARATO, Rafael. Dança, dinheiro e mercado: a economia da dança pelo viés historiográfico. In: GUARATO, Rafael (Org). Historiografia da dança: teorias e métodos. São Paulo: Annablume, 2018. p. 39-62.

KOPYTOFF, Igor. The cultural biography of things: commoditization as process. In: APPADURAI, Arjum. The social life of things. Cambridge: Cambridge University Press, 1986, p. 64-93.

LEPECKI, André. Exhausting Dance: performance and the Politics of Movement. London/New York: Routledge, 2006.

MARTíN-BARBERO, Jesús. Dos meios as mediações: comunicação, cultura e hegemonia. Rio de Janeiro: Editora UFRJ, 1997.

SANT'ANNA, Denise Bernuzzi. Ética e Cultura Corporal: Do culto do corpo às condutas In. MIRANDA, Danilo Santos de (Org). Ética e Cultura. São Paulo: Perspectiva: Sesc São Paulo, 2004.

WILLIAMS, Raymond. Cultura e sociedade. (1780-1950). São Paulo: Companhia Editora Nacional, 1969.

Recebido: 07/05/2019

Aprovado: 28/10/2019 